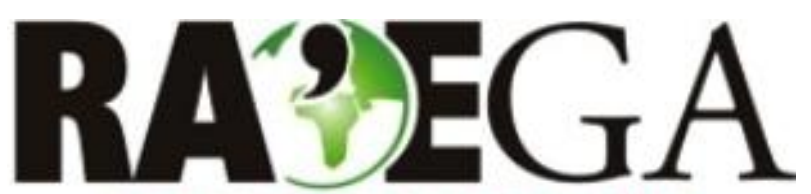

O ESPAÇO GEOGRÁFICO EM ANÁLISE

\title{
IMPACTOS SOCIOAMBIENTAIS E CONCEPÇÕES DE DESENVOLVIMENTO NO PROCESSO DA DUPLICAÇÃO DA BR-386 SOBRE A TERRA INDÍGENA JAMÃ TÏ TÃNH, EM ESTRELA, RIO GRANDE DO SUL/BRASIL*
}

\section{SOCIO-ENVIRONMENTAL IMPACTS AND DEVELOPMENT DONCEPTIONS IN THE BR-386 DUPLICATION PROCESS ON THE INDIGENOUS LAND JAMÃ TŸ TÃNH, IN ESTRELA, RIO GRANDE DO SUL / BRAZIL*}

\author{
Juciane Beatriz Sehn da Silva ${ }^{1}$, Luís Fernando da Silva Laroque ${ }^{2}$
}

\begin{abstract}
RESUMO
Os Kaingang, do ponto de vista etnolinguístico, são pertencentes à família Jê e, junto com os Xokleng, constituem os povos Jê Meridionais. Delimitando como recorte espacial a Terra Indígena Jamã Tỹ Tãnh, situada em territórios da Bacia Hidrográfica Taquari-Antas, no Rio Grande do Sul/BR, o estudo objetiva analisar os impactos socioambientais decorrentes da implantação do empreendimento de duplicação da rodovia BR-386, apontando para os desdobramentos desse projeto no que diz respeito à articulação sociopolítica das lideranças indígenas e à concepção Kaingang de desenvolvimento. Trata-se de uma pesquisa qualitativa, de caráter exploratório e de natureza descritiva. Dentre os procedimentos metodológicos, destaca-se a revisão bibliográfica sobre os Kaingang, o levantamento e a análise de fontes documentais encontradas no Ministério Público Federal de Lajeado, pesquisa de campo na Terra Indígena Jamã Tÿ Tãnh, com a elaboração de diários, registros fotográficos e entrevistas com base na metodologia de História Oral. Constatou-se a forte articulação política das Terras Indígenas situadas em territórios da Bacia Hidrográfica Taquari-Antas, Caí, Sinos e Lago Guaíba/RS, impactadas direta ou indiretamente pela duplicação da BR-386. Evidenciou-se que os principais impactos decorrentes do empreendimento relacionamse ao exercício dos saberes tradicionais, à sustentabilidade do grupo e à desapropriação de parte da área de terras ocupada. Além disso, para os Kaingang, desenvolvimento diz respeito à liberdade de vivenciar práticas culturais.
\end{abstract}

Palavras-chave: protagonismo indígena; projeto desenvolvimentista; etnodesenvolvimento.

\section{ABSTRACT}

The Kaingang, from the ethno-linguistic point of view, belong to the Jê family and together with the Xokleng, constitute the Southern Jê peoples. Delimiting as a space cutout the Jamã Tÿ Tãnh Indigenous Land, located in territories of the Taquari-Antas Hydrographic Basin, in Rio Grande do Sul / BR. This study aims to analyze the social and environmental impacts resulting from the implementation of the duplication project of the BR-386 highway, pointing for the unfolding of this project with regard to the socio political articulation of indigenous leaderships and the Kaingang conception of development. It is a qualitative, exploratory and descriptive research. Among the methodological procedures, we highlight the literature review on the Kaingang peoples, the survey and analysis of documentary sources found at the Federal Public Prosecutor's Office of Lajeado, a field research in the Indigenous Land of Jamã Tÿ Tãnh, with the elaboration of diaries, photographic records and interviews based on Oral History methodology. It was verified the strong political articulation of the Indigenous Lands located in territories of the Taquari-Antas, Caí, Sinos and Lago Guaíba Hydrographic Basin, impacted directly or indirectly by the duplication of the BR-386, and it was evidenced that the main impacts resulting from the entrepreneurship are related to the exercise of traditional knowledge, to the sustainability of the group and to the expropriation of part of the occupied land area. To the Kaingang, development refers to the freedom to experience cultural practices.

Key-words: indigenous protagonism; developmentalist project; ethnodevelopment.

Recebido em: 08/11/2016

Aceito em: 27/11/2017

\footnotetext{
${ }^{1}$ Universidade do Vale do Taquari - UNIVATES, Lajeado/RS, email: sehn@universo.univates.br

${ }^{2}$ Universidade do Vale do Taquari - UNIVATES, Lajeado/RS, email: Iflaroque@univates.br

* o estudo insere-se no Projeto de Pesquisa "Identidades Étnicas em espaços territoriais da Bacia Hidrográfica Taquari-Antas" e no Projeto de Extensão "História e Cultura Kaingang" da Universidade do Vale do Taquari UNIVATES e conta com auxílio financeiro do CNPq, FAPERGS e Univates.
} 


\section{IMPACTOS SOCIOAMBIENTAIS E CONCEPÇÕES DE DESENVOLVIMENTO NO PROCESSO DA DUPLICAÇÃO} DA BR-386 SOBRE A TERRA INDÍGENA JAMÃ TŸ TÃNH, EM ESTRELA, RIO GRANDE DO SUL/BRASIL

\section{INTRODUÇÃO}

Os Kaingang constituem uma das populações ameríndias mais numerosas do Brasil, contabilizando cerca de trinta e oito mil pessoas distribuídas nos estados de São Paulo, Paraná, Santa Catarina e Rio Grande do Sul. No Rio Grande do Sul, estima-se uma população de dezessete mil Kaingang, concentrada em Terras e Reservas Indígenas regularizadas pela União, ou que estejam na fase inicial do processo de regularização fundiária. Também ocupam diversas outras áreas, sobretudo, em contextos urbanos, próximas de rodovias federais ou estaduais (BRASIL, 2012).

O objetivo do estudo consiste em analisar os impactos socioambientais decorrentes do empreendimento de duplicação da rodovia BR-386, apontando para os desdobramentos desse projeto no que diz respeito à articulação sociopolítica das lideranças indígenas e à concepção Kaingang de desenvolvimento. A delimitação espacial da pesquisa abrange a Terra Indígena Jamã Tÿ Tãnh, localizada em contexto urbano no município de Estrela, estado do Rio Grande do Sul/BR. Tradicionalmente, este território integra as áreas de ocupação Kaingang no passado.

No âmbito do Programa de Aceleração do Crescimento, a duplicação da BR-386 figura como uma grande obra que visa, sobretudo, fomentar a economia da região do Vale do Taquari. A partir dessa realidade, busca-se evidenciar o protagonismo das parcialidades Kaingang e suas cosmovisões em relação aos impactos ambientais, sociais e territoriais, que afetam toda uma coletividade territorializada em áreas adjacentes às Bacias Hidrográficas dos rios Taquari-Antas, Caí, Sinos e Lago Guaíba, que abrange, respectivamente, as Terras Indígenas Jamã Tÿ Tãnh (Estrela); Foxá (Lajeado); Pó Nãnh Mág e Ka Mág (Farroupilha); Por Fi Gâ (São Leopoldo); $\tilde{Y}$ mã Topẽ Pẽn, $\tilde{Y}$ mã Fág Nhin e Morro Santana (Grande Porto Alegre).

Nesse sentido, é relevante entender o significado das transformações causadas pela implantação de grandes projetos e obras públicas, no caso, as duplicações das BRs, que atingem direta ou indiretamente um povo dito 'invisível', tido como sem importância. Elucidar os impactos decorrentes de projetos de desenvolvimento permite compreender também as visões das sociedades indígenas em relação ao que seja 'desenvolvimento'. Nesse sentido, podese inferir que a duplicação da BR-386 representa uma forma de desenvolvimento às avessas, na medida em que está associada, sobretudo, a um viés econômico.

A arquitetura do artigo envolve, além da introdução, a metodologia utilizada na realização do estudo, os resultados e discussões que foram embasados em teóricos de cultura como Oliveira (1996) e Pardini (2012); de território e territorialidade como Gallois (2001), Little (2002), Cabral (2007) e Castro (2007); e de desenvolvimento, como Sen (2000). Por fim, as análises decorrentes da pesquisa realizada são sintetizadas nas considerações finais.

No que tange à opção por alguns conceitos utilizados para os Kaingang, na proposta em questão, utilizamos o termo "Terra Indígena" na perspectiva do que propõe Seeger e Castro (1979), para quem o termo adquire uma dimensão de territorialidade, com significados simbólicos e culturais. Juridicamente, o termo "Terra Indígena" está previsto na Constituição Federal de 1988, no Artigo 231, como sendo as tradicionalmente ocupadas pelos indígenas (BRASIL, 1988). Já os conceitos de desenvolvimento, desenvolvimento sustentável e etnodesenvolvimento serão apresentados e definidos no decorrer do texto, nas discussões e na apresentação dos resultados.

\section{MATERIAIS E MÉTODO}

A metodologia adotada consiste numa análise qualitativa e descritiva, com abordagem etno-histórica no tratamento das fontes bibliográficas e documentais.

O método qualitativo, neste estudo, com base em Godoy (1995), é entendido como uma forma de obter dados descritivos referentes a pessoas, lugares e processos interativos, através 


\section{IMPACTOS SOCIOAMBIENTAIS E CONCEPÇÕES DE DESENVOLVIMENTO NO PROCESSO DA DUPLICAÇÃO DA BR-386 SOBRE A TERRA INDÍGENA JAMÃ TŸ TÃNH, EM ESTRELA, RIO GRANDE DO SUL/BRASIL}

do contato direto do pesquisador com a situação estudada, visando compreender os fenômenos com base na perspectiva dos sujeitos. Os dados coletados sob a forma de transcrição de entrevistas, anotações de campo, fotografias, desenhos e demais documentos visam à compreensão do objeto de estudo. Ainda, considera-se que todos os dados da realidade são importantes e devem ser examinados.

Com o intuito de entranhar nas questões culturais, nas estruturas sociais e nos processos históricos singulares, optou-se pelo método da História Oral. Segundo Alessandro Portelli (1997), a essencialidade do sujeito entrevistado é salientada pelo fato de a História Oral dizer respeito a versões do passado, ou seja, memórias. $O$ ato e a arte de lembrar são profundamente pessoais. A memória é social e torna-se concreta quando mentalizada pelas pessoas. Dessa forma, colocamo-nos numa postura de ouvintes, mantendo a pauta flexível, para que os interlocutores também pudessem falar o que consideravam importante, e não somente o que nós, pesquisadores, "desejávamos saber".

Frente ao exposto, destaca-se que, para esta pesquisa, foram realizadas observações participantes no período de janeiro de 2015 a setembro de 2016, com registros em diários de campo e entrevistas na Terra Indígena Jamã Tÿ Tãnh, com o intuito de promover aproximação e interação entre o pesquisador e os sujeitos interlocutores, a fim de propiciar a produção primária de dados. Todas as entrevistas foram concedidas mediante o prévio consentimento dos entrevistados e das lideranças políticas da Terra Indígena. Perguntas abertas e semiestruturadas caracterizaram as entrevistas, realizadas com lideranças políticas da Terra Indígena Jamã Tÿ Tãnh.

Para preservar a identidade dos interlocutores, os entrevistados foram nomeados como EA e EB (2016) e EF (2016). As entrevistas foram registradas em áudio, com o auxílio de máquina digital e gravador e, posteriormente, transcritas, optando-se por respeitar, no texto, a expressão original. Os dados coletados durante as entrevistas foram desgravados e retornados aos interlocutores para análise. Os entrevistados poderiam manter ou tirar informações transcritas, bem como, acrescentar novas informações. Posteriormente, foi feita a tabulação dos dados e a análise das informações coletadas.

Os estudos de campo foram acompanhados de pesquisa documental, bibliográfica e iconográfica. Nesse sentido, conforme referido, foram consultados os arquivos públicos no Ministério Público Federal, em Lajeado, bem como, o acervo dos Projetos de Pesquisa e de Extensão da UNIVATES, no que diz respeito à utilização de entrevistas, diários de campo e acervo jornalístico. Ainda, fez-se uso de fontes jornalísticas de acesso público, por meio da homepage digital de jornais que circulam na região do Vale do Taquari.

A revisão da literatura constituiu-se numa etapa essencial do estudo, uma vez que, por meio dela, foi possível tecer informações sobre aspectos culturais dos Kaingang. Esses estudos foram importantes para ampliar a compreensão da história Kaingang e de suas percepções sobre territorialidade, natureza, relações com os não-índios, bem como, ajudaram a compreender a lógica da presença indígena em contextos urbanos. Os teóricos escolhidos para fundamentar o presente estudo serviram, sobretudo, para embasar as interpretações realizadas durante a análise dos dados coletados na pesquisa, possibilitando, a partir dos conceitos trabalhados por cada um deles, enriquecer a análise e a leitura do objeto de pesquisa.

A área de estudos possui, aproximadamente, 14 hectares, sendo grande parte ocupada por habitações e benfeitorias, como escola, Casa de Fala, Casa do Artesanato, área de plantio e cemitério. Uma outra parte está coberta por uma vegetação em estágio de regeneração, composta por plantas nativas e algumas espécies exóticas. Toda essa organização pode ser observada no etnomapa (Figura 1), elaborado em conjunto com a comunidade 


\section{IMPACTOS SOCIOAMBIENTAIS E CONCEPÇÕES DE DESENVOLVIMENTO NO PROCESSO DA DUPLICAÇÃO DA BR-386 SOBRE A TERRA INDÍGENA JAMÃ TŸ TÃNH, EM ESTRELA, RIO GRANDE DO SUL/BRASIL}

indígena, que definiu e informou os elementos Indígena em questão. do universo humano e não-humano da Terra

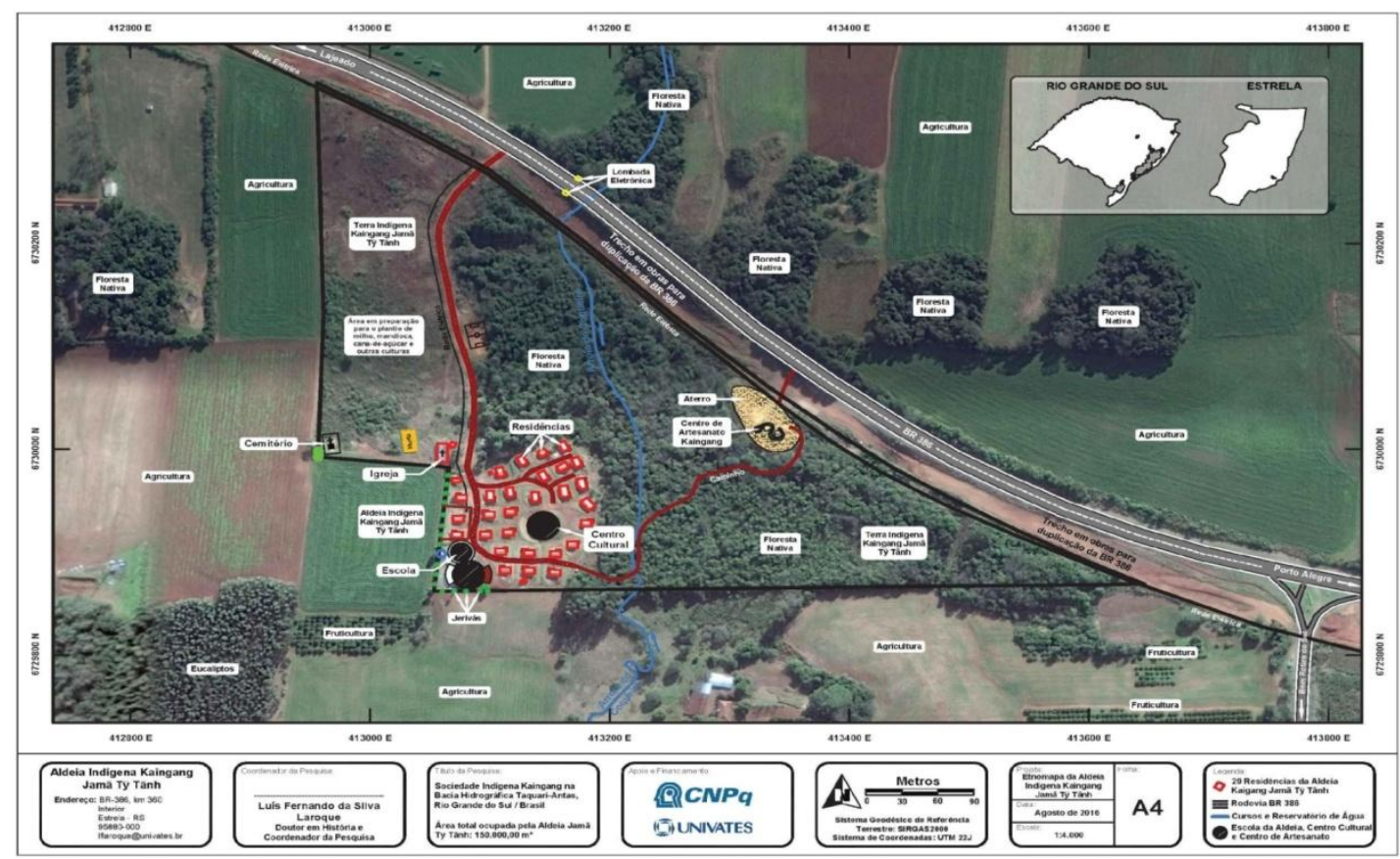

Figura 1 - Etnomapa da Terra Indígena Jamã Tÿ Tãnh/Estrela. Fonte: Acervo dos Projetos de Pesquisa sobre Kaingang e Identidades Étnicas da UNIVATES.

\section{RESULTADOS E DISCUSSÃO}

Diversos coletivos Kaingang, que hoje ocupam áreas de terras nas cidades de Lajeado, Estrela, Farroupilha, Tabaí, São Leopoldo e Porto Alegre, no estado do Rio Grande do Sul, intensificaram o movimento de (re)territorialização, sobretudo, a partir da segunda metade do século $X X$, vindo a ocupar antigos espaços de memória, reconhecidos como parte de seus tradicionais territórios. Dessa forma, questões culturais e de sustentabilidade desses grupos concorrem para a organização de comunidades indígenas em contextos urbanos, que passam a atuar em defesa das terras ocupadas e de preceitos previstos na Constituição Federal de 1988.

Todavia, surgem diversas tensões relacionais entre indígenas e não-índios nos espaços ocupados em contextos urbanos, na medida em que há interesses distintos em relação a esses territórios, além de eles também serem sujeitos de direitos. Sob a égide do desenvolvimento, diversas ações, como, por exemplo, a construção e a duplicação de rodovias, que causam impactos de toda ordem, sobrepõem-se, muitas vezes, ao direito dos povos indígenas, dando origem a diversos conflitos, sobretudo, relacionados ao direito indígena à terra.

Em princípio, impactos socioambientais e territoriais marcam a história de contato entre os Kaingang e não-índios, sobretudo, a partir do século XIX. Nesse sentido, a duplicação da BR-386 pode ser analisada como a continuidade de um processo engendrado há mais tempo, em que os interesses das sociedades urbano-industrialcapitalistas implicam inúmeros danos ao modo de vida dos nativos. O que há de novo é que a Constituição Federal de 1988 serviu e serve de apoio às lutas indígenas, no sentido de prever a obrigatoriedade do cumprimento por parte do poder público, bem como, de uma série de medidas compensatórias e mitigatórias, na tentativa de minimizar os impactos sofridos em 


\section{IMPACTOS SOCIOAMBIENTAIS E CONCEPÇÕES DE DESENVOLVIMENTO NO PROCESSO DA DUPLICAÇÃO DA BR-386 SOBRE A TERRA INDÍGENA JAMÃ TŸ TÃNH, EM ESTRELA, RIO GRANDE DO SUL/BRASIL}

decorrência da implantação de grandes obras de desenvolvimento.

Em relação à duplicação da BR-386, uma das lideranças da Terra Indígena Jamã Tÿ Tãnh, Maria Antônia Soares, partindo da concepção de território alargado, decidiu chamar as lideranças de outras Terras Indígenas, igualmente situadas em contextos urbanos nas cidades de Lajeado, Porto Alegre, São Leopoldo e Farroupilha, para "lutar" pelos direitos indígenas. Questionados sobre as circunstâncias que teriam levado a essa articulação política, ouviu-se o seguinte de alguns interlocutores da pesquisa:

EA: Isso foi através da Maria Antônia que fez, ela que fez essa..., ela fez como eu posso dizê, uma... Eu sei que é lá de Porto Alegre, Morro do Osso, Lomba do Pinheiro, a Safira, e a de Lajeado, São Leopoldo e Farroupilha também, daí da 7, entre essas aí. Dessas, 6 são de fora. Essas 6 tava sempre ajudando, lutando com ela, nossa luta aqui, junto acompanhando, ajudando ela a lutar pela nossa terra, ali foi aonde ela fez uma parceria com eles, ela disse "Não, vocês são meus parente, vocês tão sempre me ajudando assim na questão", porque ela não sabia estar por dentro, eles vieram, ajudaram ela, deram força [...] (EA e EB, 10/02/2016, p. 3).

Verifica-se, no relato anterior, a configuração de uma "trama social" caracterizada por certo dinamismo entre as lideranças Kaingang que, assim como no passado, uniram forças por meio de alianças políticas que visam satisfazer interesses próprios, na tentativa de reaver, pelo menos em parte, as perdas sofridas durante largo processo histórico, sobretudo, em relação à terra. De acordo com Oliveira (1996), o território indígena deve ser compreendido como um espaço político onde os usos e costumes indígenas são colocados explícita e intencionalmente como soberanos.

A questão da aliança também é evidenciada na fala de outra representatividade
Kaingang da Terra Indígena Ỹmã Topẽ Pẽn, situada em Porto Alegre/RS, ao afirmar que "nóis trabalhemo assim, é tudo parentagem, é tudo parentesco né! Já pra começa, pra não caí fora da nossa cultura, tem as nossas marca que já é parentesco. [...] dessa forma que nóis trabalhemo, que nóis se unimo pra consegui esse recurso, esse nosso direito" (EG, apud SILVA, 2011, p.71).

Esse relato deixa claro que a união entre as comunidades indígenas justifica-se pela lógica do parentesco. Assim como o mito de origem Kaingang apresenta a complementaridade entre os irmãos Kamé e Kairu como fórmula de organização social que estabelece regras de descendência e de casamento, é possível verificar na narrativa do entrevistado $G$, a manutenção dessa prática cultural, que justifica a interconexão e a união entre as Aldeias em prol de uma "luta" comum.

Retomando a ideia de 'território alargado', evidenciada nos parágrafos anteriores, sob o qual os Kaingang estabelecem relações de aliança e de reciprocidade interaldeã, recorre-se aos estudos de Cabral (2007), para fundamentar essa concepção, na qual o território é entendido como um espaço mobilizado e a territorialidade como a legitimidade para firmar o controle sobre um espaço geográfico. Aplicando as concepções do referido autor aos Kaingang, pode-se depreender que o território tem a ver com uma rede de relações vividas; portanto, não se faz necessário um enraizamento material para que determinado espaço seja concebido como território.

O Relatório Complementar do Componente Indígena (2008) classificou e justificou a ocorrência de duas áreas de influência, com base na realização das obras de duplicação da rodovia BR-386. Conforme Almeida e Fernandes (2010, p.3), isso se deve à ocorrência de uma "unidade política territorial pan aldeã" causada pela organização do empreendimento, ou seja, devido à articulação entre grupos locais, referida nos parágrafos anteriores. Desta forma, estabeleceu-se uma área de influência direta 
(AID), composta pela Terra Indígena Jamã Tÿ Tãnh, em Estrela e pela Terra Indígena Foxá, em Lajeado; e uma área de influência indireta (All), formada por duas Aldeias Kaingang nos municípios de Farroupilha; uma, em São Leopoldo; e três no município de Porto Alegre (Morro do Osso, Lomba do Pinheiro e Morro Santana) ${ }^{2}$, conforme mapa (Figura 2).

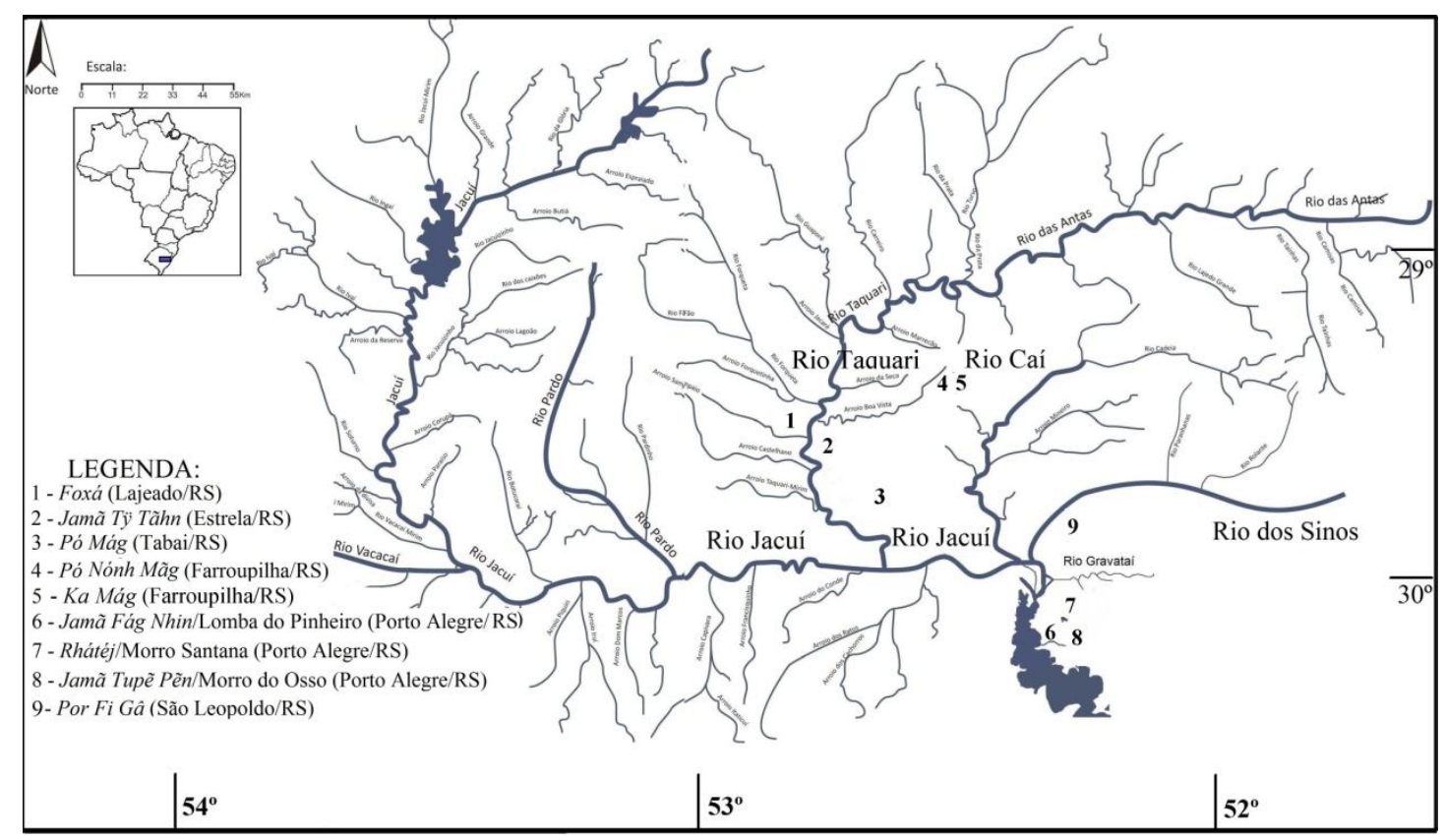

Figura 2 - Mapa das Terras Indígenas Kaingang impactadas pela duplicação da BR-386. Fonte: Acervo dos Projetos de Pesquisa sobre Kaingang e Identidades Étnicas da UNIVATES.

Tomando como ponto de partida os impactos ambientais, cita-se como exemplo a supressão vegetal, que afeta o exercício dos saberes tradicionais e a sustentabilidade dos Kaingang, na medida em que a área a ser suprimida para a duplicação da rodovia representa um espaço de existência efetiva da Terra Indígena Jamã Tÿ Tãnh e uma importante reserva de uso para as Comunidades Indígenas de Lajeado e da Grande Porto Alegre. Assim, as

\footnotetext{
${ }^{2}$ Cabe destacar que durante os trâmites de negociação das compensações territoriais, a T.I Foxá, na pessoa da liderança Francisco dos Santos Rokág, negocia com o DNIT e a Funai uma área de terras de 11,6 hectares na cidade de Tabaí, onde é criada a Terra Indígena Pó Mág. Portanto, ocorre o surgimento de uma nova área de impacto direto, sendo um desdobramento da T.I Foxá, havendo uma divisão de parte do grupo que habitava a Foxá, fato ocorrido em 2013, uma vez que Francisco com sua família irão deslocar-se para essa nova área. Posteriormente, irão somar-se ao grupo, mais cinco famílias (BUSOLLI, 2015). Com a criação dessa nova T.I, as áreas impactadas passam a totalizar 9 T.I.
}

pequenas áreas de vegetação que se desenvolvem nas margens das rodovias públicas de propriedade da União tornam-se espaços de uso potencial, nos quais os Kaingang buscam a matéria-prima para a confecção do artesanato, coletam plantas tradicionais usadas em sua alimentação ou mesmo em sua medicina tradicional (ALMEIDA; FERNANDES, 2010). Estes espaços são, na lógica nativa, extensão de seus territórios, que, ao serem afetados, comprometem a vida como um todo.

O impacto ambiental também reflete diretamente na pequena área de mata da Terra Indígena Jamã Tÿ Tãnh, que, segundo relatos dos interlocutores da pesquisa, constituiu-se com a própria intervenção do grupo, na pessoa do patriarca Manoel Soares, que, durante a busca por matéria-prima para a confecção de artesanato na beira da rodovia, tinha o costume de trazer mudas de árvores frutíferas e nativas para serem plantadas na área da "Aldeia Velha". 


\section{IMPACTOS SOCIOAMBIENTAIS E CONCEPÇÕES DE DESENVOLVIMENTO NO PROCESSO DA DUPLICAÇÃO DA BR-386 SOBRE A TERRA INDÍGENA JAMÃ TŸ TÃNH, EM ESTRELA, RIO GRANDE DO SUL/BRASIL}

Nesse sentido, o relato a seguir ilustra essa questão:

[...] quando passasse a duplicação eles queria tira aqueles arvoredo de lá, eu que falei com o $\mathrm{X}$ e disse pra ele, não, isso é meio injusto tira, que isso é plantação do falecido meu pai, tire o que vocês pude tira que não atingi a duplicação, isso aí vocêis deixa né, isso é a lembrança que ele deixo [...]. Daí eles combinaram assim com nóis, a Maria inda era viva naquela época. Ele disse "Não, nóis vamos tirá o que nóis pude de arvoredo e coisa, mais nóis vamo doa de novo pra vocêis" [...] (EF, 28/07/2016, p.3).

Portanto, é possível constatar que a questão não é apenas repor a área a ser suprimida, conforme proposto em medida compensatória específica, mas de compreender o significado que lhe é atribuído por esse grupo. No entender dos Kaingang, as árvores da $\tilde{Y} m \tilde{a}$ Si (Aldeia Velha) representam o legado deixado pelo patriarca. Há uma relação afetiva e simbólica relacionada às plantas, que, mesmo sendo repostas, aquelas que o pai plantou não estarão mais lá. Há uma dupla perda: do pai que não está mais entre eles na forma física, e da "morte" das árvores, que representavam a presença viva/espiritual, do pai no local.

A questão que se evoca tem a ver com a ideia de tempo vivido, tempo passado, o "wãxi", que carrega lembranças de uma época, assim como há o respeito ao tempo e à vida da natureza. Essa questão nos é confidenciada na fala de outro interlocutor indígena $E A$, ao referir que "Ah, vocêis vão da outras pra nóis, mas não vão da com as frutas que nóis temo ali, nóis vamo ter que espera muitos anos pra ter de novo" (EA e EB, 10/02/2016, p.6), o que aponta a importância desse espaço como locus de sua cultura, de um ethos que está marcado na vida da natureza e que possui todo um significado para a reprodução física e simbólica do grupo.
Recorrendo aos estudos de Pardini (2012), poder-se-ia associar a fala à constituição das "matas culturais", que consiste no manejo de espécies vegetais pelos povos indígenas, na prática desempenhada pelo patriarca Manoel Soares que, ao trazer espécies de árvores nativas e frutíferas de outros lugares para serem plantadas na área ocupada pelo grupo, reflete o cultivo inscrito nas práticas culturais sobre o fundo de "natureza". Nesse sentido, seria próprio afirmar que a pequena área de mata que hoje permeia a Terra Indígena Jamã Tÿ Tãnh constituiu-se também a partir do plantio e do transplante de espécies vegetais pelos próprios Kaingang, ou seja, do "manejo florestal indígena".

Teoricamente, o estudo de Eduardo Viveiros de Castro (2007) sobre as concepções indígenas em relação à "natureza" ajuda a compreender melhor a relação dos Kaingang com o seu ambiente. Tomando como exemplo o ambiente amazônico, Viveiros de Castro considera que boa parte da cobertura vegetal amazônica é resultado de milênios de intervenção dos povos indígenas que lá viveram. Dessa forma, inúmeras plantas úteis da região proliferam diferentemente em função das técnicas indígenas de aproveitamento do território. Segundo este autor, o que se chama de "natureza" é parte e resultado de uma longa história cultural e de uma aplicada atividade humana.

Semelhante às sociedades indígenas de qualquer parte da região amazônica, seria justo afirmar que, para os Kaingang, natureza e cultura estão imbricados. Contribui com essa discussão a afirmação de Pardini (2012, p.593), segundo o qual, "No universo indígena, tudo é Cultura (não há Natureza)". Há uma sintonia social entre os indígenas e a natureza mediada por formas específicas de organização sociocosmológica.

Em relação aos impactos territoriais, houve a necessidade de desapropriação de parte da área ocupada pela Terra Indígena Jamã Tÿ Tãnh. Como compensação das perdas territoriais sofridas, o Relatório de Impacto Ambiental do Componente Indígena prevê, como medida 


\section{IMPACTOS SOCIOAMBIENTAIS E CONCEPÇÕES DE DESENVOLVIMENTO NO PROCESSO DA DUPLICAÇÃO DA BR-386 SOBRE A TERRA INDÍGENA JAMÃ TŸ TÃNH, EM ESTRELA, RIO GRANDE DO SUL/BRASIL}

compensatória, a aquisição de 120 hectares de terras (GONÇALVES, 2008). Nesse sentido, o subprograma de aquisição fundiária, constante no Plano Básico Ambiental do Componente Indígena, refere que a composição da unidade política territorial, incluindo as comunidades indígenas do Vale do Taquari, do Caí e as comunidades da Grande Porto Alegre, levou a uma divisão equitativa da área de terras entre as sete Aldeias (ALMEIDA; FERNANES, 2010).

Essa divisão foi uma iniciativa da própria líder, Maria Antônia Soares, que resolveu incluir todo o seu povo nessa compensação territorial. Dessa forma, a parte territorial a ser compensada em decorrência da supressão vegetal ficou em 18 hectares para a Terra Indígena de Estrela e 17 hectares para cada uma das outras seis comunidades indígenas. A Terra Indígena Jamã Tÿ Tãnh, além dos 18 hectares da referida divisão, conforme Almeida e Fernandes (2010), deverá ser beneficiada com mais 15 hectares como complemento da área de vegetação a ser suprimida, especificamente para a recomposição vegetal e o manejo de material vegetal (artesanal, frutíferas e medicinais) de uso da comunidade, totalizando 33 hectares de terra.

Com base nos dados da Procuradoria da República do município de Lajeado/RS, constatou-se, em relação ao programa de aquisição das terras, que a comunidade indígena Jamã Tÿ Tãnh teria uma área de 6,7 hectares desapropriada em 2012, uma área de 5,4 hectares e outra de 1,8 hectares, declaradas de utilidade pública, em 22 de maio de 2013. A Terra Indígena Foxá teria, por direito, 17 hectares, tendo sido adquiridos 11,6 hectares no município de Tabaí, além do direito a uma área remanescente de 5,4 hectares. Todas as outras Terras Indígenas fazem jus a uma área de 17 hectares; no entanto, São Leopoldo teria uma área de 8,3 hectares com declaração de utilidade pública datada de 20 de maio de 2013; Lomba do Pinheiro teria uma área de 22 hectares com declaração de utilidade pública datada de 23 de junho de 2013; Morro do Osso teria uma área de 29 hectares com declaração de utilidade pública;
Vila Safira teria uma área de 3,5 hectares com declaração de utilidade pública datada de 11 de setembro de 2013; Farroupilha teria uma área de 3 hectares já identificada (CERTIDÃO de 17/09/2013, MINISTÉRIO PÚBLICO FEDERAL).

Em se tratando dos impactos sociais decorrentes da implantação da obra, destaca-se a inviabilização de 10 casas do total de 16 construídas na área da Aldeia Antiga; da escola indígena, situada na área da Aldeia Velha; e dos espaços de venda de artesanato às margens da rodovia (ALMEIDA; FERNANDES, 2010). Apoiados no documento intitulado "Nota técnica Programa de Apoio às Comunidades Kaingang" (2012), elaborado com a finalidade de informar a respeito do status de desenvolvimento das ações previstas no Programa de Apoio às Comunidades Kaingang, constatou-se que tais impactos seriam compensados com a construção de 29 casas de alvenaria abastecidas com água, energia elétrica e com sistema de fossas sépticas; a construção de uma nova escola, da Casa de Fala e da Casa de Artesanato, além de um galpão rústico para realizar encontros entre as Terras Indígenas.

O projeto da nova Aldeia foi aprovado em 21 de março de 2012, em reunião realizada com a FUNAI e com lideranças da Comunidade Kaingang de Estrela (NOTA TÉCNICA de 16/04/2012, Ministério Público Federal). Ainda, em virtude da indisponibilidade da rodovia como local de coleta de matéria-prima para produção de artesanato, foi proposta a aquisição de 10 quilogramas de sementes por família para a confecção de artesanato, além da concessão de uma cesta básica por família, durante o período de construção da rodovia (ALMEIDA; FERNANDES, 2010).

Em relação aos impactos sociais, a Aldeia nova representa uma melhoria, na medida em que as novas casas possibilitam melhor proteção contra as ações do tempo, por ter acesso à água, à energia elétrica e ao saneamento básico em todas as moradias (DIÁRIO, 23/05/2016). Todavia, conforme indicam Zhouri e Laschefski (2010), é preciso estar atento, pois, em se tratando de impactos sociais decorrentes da 


\section{IMPACTOS SOCIOAMBIENTAIS E CONCEPÇÕES DE DESENVOLVIMENTO NO PROCESSO DA DUPLICAÇÃO} DA BR-386 SOBRE A TERRA INDÍGENA JAMÃ TŸ TÃNH, EM ESTRELA, RIO GRANDE DO SUL/BRASIL

implantação de grandes obras de desenvolvimento, muitas vezes, a diversidade da experiência social vê-se reduzida a um conjunto material homogêneo, composto por benfeitorias e edificações. Embora os indígenas não tenham apontado, essa questão poderia ser mencionada em relação à planta arquitetônica das casas, que nos parece ser muito padronizada, pois contemplou muito pouco, aspectos da cultura Kaingang, diferente da Casa de Artesanato e da Escola Kaingang Bilíngue Manoel Soares, que foram projetadas com base em pesquisas antropológicas, trazendo elementos da cultura desse grupo. Percebe-se que são casas projetadas para um modelo de família uninuclear, que não dá conta de abarcar a complexidade das relações de sociabilidade vividas pelos Kaingang, como, por exemplo, no caso de visita de parentes, aumento do número de integrantes da família, possibilidade de o genro vir morar na casa do sogro, entre outros aspectos, próprios da cultura Kaingang.

\subsection{CONCEPÇÃO KAINGANG DE "DESENVOLVIMENTO" VERSUS DUPLICAÇÃO DA BR-386}

Na essência, a duplicação da rodovia BR386 entre Estrela e Tabaí representa, em nível estadual, uma obra que visa fomentar o "desenvolvimento" da região do Vale do Taquari e, em nível nacional, o "crescimento" do país. Justificativas de ordem social figuram entre as motivações periféricas para a realização da obra (no caso, acidentes de trânsito com vítimas fatais). A prevalência de motivações é, portanto, fins econômicos, o que fica bem evidenciado na reportagem publicada no site do DNIT:

[...] O empreendimento vai beneficiar a economia gaúcha e o crescimento do país porque a rodovia é uma das principais artérias de escoamento de safras agrícolas. [...]

Além de soja, milho, trigo, erva-mate e produtos da avicultura e suinocultura, pela BR-386 passa a produção de pedras semipreciosas no município de
Soledade. No que diz respeito à multimodalidade, destaque é o terminal rodo-hidro-ferroviário de Estrela, onde é feito o transbordo da soja para o Super-porto de Rio Grande. [...] (DNIT, 15/03/2011, Texto digital, grifo nosso).

Posição semelhante à da reportagem anterior pode ser colhida no Relatório de Impacto Ambiental das obras de duplicação da BR-386 (ROSA, 2009, p.13). No item "Por que a rodovia deverá ser duplicada?", consta que os principais motivos seriam: a "redução do número de acidentes, a redução dos custos com transporte e a consequente promoção de um vetor de desenvolvimento econômico para a região". Portanto, em ambas as fontes, aparece intrínseca a ideia de "desenvolvimento" do capital. É uma concepção restrita de desenvolvimento associada, sobretudo, ao crescimento econômico, uma vez que destaca a produção e o escoamento de commodities (produtos agropecuários e minerais), visando beneficiar a "economia gaúcha" e o "crescimento do país".

Frente ao exposto, faz-se necessário esclarecer que desenvolvimento e crescimento econômico são palavras que se relacionam, porém não são sinônimas. Segundo Susini e Cabrera (2010), o crescimento econômico é uma simples variação quantitativa, enquanto o desenvolvimento envolve mudanças qualitativas no modo de vida das pessoas e das instituições.

Para um melhor entendimento do que possa significar desenvolvimento para os Kaingang da Terra Indígena Jamã Tÿ Tãnh, foram indagados os interlocutores pesquisados e obteve-se a seguinte resposta:

Pra nóis, assim... Eles acha assim que vai aumenta, que vai dar mais lugar. Tá, mais pra nóis, como é que fica? A respeito de quere passa ali, a velocidade que eles passam também! Agora esse medo que a gente já tem que deu ali [refere-se à morte de 4 jovens Kaingang, vítimas do rodado de 


\section{IMPACTOS SOCIOAMBIENTAIS E CONCEPÇÕES DE DESENVOLVIMENTO NO PROCESSO DA DUPLICAÇÃO DA BR-386 SOBRE A TERRA INDÍGENA JAMÃ TŸ TÃNH, EM ESTRELA, RIO GRANDE DO SUL/BRASIL}

um caminhão], daí o nosso desenvolvimento como é que vai se, com medo? [...] tem que ir pro lado do acostamento, [...] as veis vai na Glória busca uma carne, as veis não tem pra $\mathrm{i}$ no mercado, daí a gente faiz troquinho, faiz ali que é perto, isso vai se perigo também pra nóis (EA e EB, 10/02/2016, p.5).

Verifica-se que, na lógica indígena, "desenvolvimento" diz respeito à liberdade, no sentido de poder movimentar-se pelo espaço, sem medo; liberdade de fazer suas escolhas de vivenciar práticas culturais através do que nosso sujeito da pesquisa refere como fazer "troquinho", ou seja, vender o artesanato a fim de obter moeda de troca para comprar alimentos.

Há também a preocupação com a vida humana que acaba sendo "atingida" por esse modelo de "desenvolvimento" que privilegia o capital. Quando nosso interlocutor refere que "eles acha assim que vai aumenta, que vai dar mais lugar", ele está se referindo ao aumento do fluxo da BR-386 e ao perigo que o tráfego intenso Ihes causa, tendo em vista que a rodovia representa uma extensão de seu território de "coleta" e de mobilidade. Em seguida, aparece a pergunta que nos parece ser o cerne da questão: "o nosso desenvolvimento como é que vai se?". Aqui talvez os indígenas estejam sinalizando para o que devesse ser entendido, na perspectiva de Amartya Sen (2000), como um processo de expansão do desenvolvimento de suas liberdades substantivas. Ou seja, de ter condições de evitar privações como a fome, por exemplo.

Nesse sentido, convém considerar algumas concepções teóricas em torno dos conceitos de "desenvolvimento", "desenvolvimento sustentável" e "etnodesenvolvimento", abordados nesse estudo. Para tanto, ao situar no tempo a origem do termo "desenvolvimento", constata-se que ele surge por volta dos séculos XII e XIII, com o sentido de "revelar", de "expor", passando a admitir sentidos mais complexos por volta de
1850, quando passou a admitir diversas conotações, dependendo do adjetivo que o qualifica: social, humano, econômico, ambiental, infantil, nacional, regional, equilibrado, sustentável, entre outros. E, como se não fosse suficiente, cada uma dessas conotações pode comportar mais de uma compreensão. Por exemplo, sob o ponto de vista econômico, a expressão "desenvolvimento" pode ser vista como o processo de crescimento do Produto Interno Bruto (PIB), ou como modernização, ou como industrialização (ANJOS FILHO, 2009).

Gallois (2001, p.175) explica que, no contexto de surgimento da noção e da prática de desenvolvimento, três aspectos surgem como fundamentais: "o indivíduo atomizado como unidade de referência do social, a domesticação e a exploração dos recursos naturais, sem preocupação com sua renovação e a mistificação da ciência e da técnica, como motor do progresso". Tais características evidenciam a relação estreita de desenvolvimento com a ideia de "progresso", que perdurou durante largo tempo no imaginário das relações e concepções ocidentais.

Amartya Sen (2000) sublinha que uma concepção adequada de desenvolvimento deve ir muito além da acumulação de riqueza e do crescimento do Produto Nacional Bruto e de outras variáveis relacionadas à renda. Assim, crescer não significa desenvolver, partindo do pressuposto de que o desenvolvimento é integral: social, humano, econômico, político, educacional, ambiental. Nesse sentido, pode-se afirmar que a duplicação da BR-386 representa um desenvolvimento às avessas, na medida em que privilegia, sobretudo, o viés econômico.

A partir do momento em que se chegou à conclusão de que o desenvolvimento não poderia ser mero sinônimo de crescimento econômico, os esforços foram dirigidos à busca de modelos alternativos, dando origem à noção de "desenvolvimento sustentável". Desta forma, situando a mudança de paradigma em relação à ideia que perdurou durante largo tempo sobre "desenvolvimento", marcada por desastrosas 


\section{IMPACTOS SOCIOAMBIENTAIS E CONCEPÇÕES DE DESENVOLVIMENTO NO PROCESSO DA DUPLICAÇÃO DA BR-386 SOBRE A TERRA INDÍGENA JAMÃ TŸ TÃNH, EM ESTRELA, RIO GRANDE DO SUL/BRASIL}

consequências sociais e ambientais, avista-se, em meados das décadas de 1970 e 1980, o início de importantes debates em nível internacional, entre os quais podem ser citados os que ocorreram na Conferência de Estocolmo, em 1972, e na Conferência da ONU Rio 92 (ECO 92), que marcaram o surgimento de um novo "modelo" de desenvolvimento, que deveria ser construído sob a tríade economia-ecologiaequidade social (ZHOURI; LASCHEFSKI, 2010).

Contudo, Zhouri e Laschefski (2010) salientam que houve uma inversão de sentido, tendo em vista que o discurso sobre "desenvolvimento sustentável", que surge a partir de então, adota um sentido diferente daquele pretendido pelos "povos da floresta", pois há uma dicotomia entre os modos de vida dos grupos indígenas (apropriação simbólica e material da natureza) e a sociedade urbanoindustrial. Dessa forma, a consequência que se consolida pode ser notada e relacionada ao projeto de duplicação da BR-386 entre Estrela e Tabaí, uma vez que, ao adotar ações de prevenção aos impactos através de medidas de mitigação e de compensação para os danos ambientais, promove uma adequação entre os interesses econômicos, ambientais e sociais, afirmando assim uma tentativa de "moldar" o modelo clássico de desenvolvimento.

Nesse contexto, a partir da década de 1970, a noção de desenvolvimento sustentável para os grupos indígenas ganha força, com base na autonomia e na defesa da identidade cultural. Esse movimento recebe o nome de "etnodesenvolvimento", termo cunhado pelos antropólogos. Esse novo paradigma propõe que as comunidades indígenas sejam as gestoras efetivas de seu próprio desenvolvimento e que tenham autonomia sobre suas terras, bem como, sobre os recursos naturais nela existentes, no sentido de elas próprias definirem os projetos a serem desenvolvidos, à luz de sua cultura, de seus valores e das suas aspirações (ANJOS FILHO, 2009).

Portanto, a medida compensatória relativa à construção da Casa de Artesanato, que foi pensada pelos Kaingang da Terra Indígena Jamã Tÿ Tãnh como um espaço promotor de cultura e de sustentabilidade, poderia ser relacionada a um projeto de "etnodesenvolvimento", na medida em que torna-se um lugar em que a arte, além de ser fonte propulsora de renda para as famílias, poderá ser um meio de interlocução com a sociedade não índia. Durante incursões na Aldeia, dialogou-se com as lideranças sobre suas pretensões em relação a este novo espaço que substitui as antigas barracas de artesanato existentes à beira da rodovia.
J: Como é que vai ser esse espaço da venda do artesanato, como vocês pensam em organizá-lo?
EA: Organiza é faze uma loja, faze nossas venda de artesanato.
J: Como a venda vai acontecer ali? Por família?
EA: Não, não é por família! A família vai botá o artesanato ali, só que a gente vai faze assim oh, cada um pelo menos vai e cuida pelo menos uma vez ao dia, vai tá todo o artesanato ali, e botou o preço, é aquele preço, ninguém vai dize assim "O meu é tanto, o dele é tanto", vai ser tudo igual, tudo o mesmo preço os artesanato que vai está ali. Só que a gente vai faze assim: um cuida uma semana, e o outro cuida no outro, mas sempre vendendo ali, organizando a venda. Se vendeu aquilo ali, isso aqui é do fulano, deixa separado, se vendeu esse aqui é dele, então deixa o dinheiro dele separado [...] (EA e EB, 10/02/2016, p.5-6).

Observa-se que há um planejamento que perpassa por uma concepção própria de gestão e de autonomia de organização do espaço, de combinação equitativa dos valores da arte comercializada e do senso de justiça em relação à distribuição desses valores. Embora seja usado o termo "loja", comum à cultura não índia, o entendimento em relação a este espaço passa 


\section{IMPACTOS SOCIOAMBIENTAIS E CONCEPÇÕES DE DESENVOLVIMENTO NO PROCESSO DA DUPLICAÇÃO DA BR-386 SOBRE A TERRA INDÍGENA JAMÃ TŸ TÃNH, EM ESTRELA, RIO GRANDE DO SUL/BRASIL}

por uma lógica nativa, com objetivos voltados para toda coletividade.

Historicamente, a relação indígena com as diversas formas de desenvolvimento é marcada por muitas perdas, porém, conforme afirma Anjos Filhos (2009), pretendem aprender, agora, como uma relação pode ser transformada em favor de seus interesses. Paul Little (2002) contribui com essa discussão, ao pontuar que, na esfera econômica, as práticas de etnodesenvolvimento tendem a ocupar o lugar de "alternativas" econômicas, particularmente, onde a ideologia neoliberal é predominante. Enfatiza que o nível principal em que se trabalha o etnodesenvolimento é o local, justamente porque, nesse nível, existem maiores oportunidades para os grupos étnicos exercerem influência nas decisões que lhes afetam e, como consequência, promover mudanças nas suas práticas econômicas e sociais. Segundo Little (2002), é no nível local que começa o processo de construção da autogestão étnica.

A concepção de desenvolvimento para os Kaingang da Terra Indígena Jamã Tÿ Tãnh/Estrela também é perpassada pela garantia de um espaço territorial mais amplo, não só para possibilitar melhores condições de sustentabilidade, mas, também, como exigência de sua organização social. No relato de um interlocutor, quando questionado sobre qual seria a maior preocupação dos Kaingang relacionada à questão de "desenvolvimento", ele responde que "A maior preocupação é com as criança né [...]". E quando questionado sobre a importância da terra, destaca que "É muito importante pras nossa criança também. Isso fica tudo pras nossas criança. É pranta, pra produzi mais alimento pra eles, negócio de artesanato também, pranta um cipó" (EF, 28/07/2016, p.9).

Trata-se, portanto, de uma concepção de desenvolvimento projetada na pessoa humana e na garantia de terras para as próximas gerações. Há uma preocupação recorrente na Terra Indígena Jamã Tÿ Tãnh para que no futuro as crianças possam continuar produzindo seu próprio alimento, seja através do cultivo da terra ou proveniente da confecção e venda de artesanato, que se torna uma complementação da subsistência física do grupo e uma forma de viver na cultura indígena. Por isso, necessitam de terra para se desenvolver no sentido mais amplo da palavra, relacionada ao bem viver, não em termos materiais ou econômicos, mas socioculturais.

\section{CONSIDERAÇÕES FINAIS}

Finalizado o estudo, é preponderante considerar que entre os principais impactos sofridos pela Terra Indígena Jamã Tÿ Tãnh com a implantação da obra de duplicação da BR-386, no trecho entre Estrela e Tabaí/RS, destaca-se: a supressão vegetal que afeta os saberes tradicionais, expressos através da coleta de matéria-prima para produção do artesanato, da busca de plantas medicinais e para a alimentação; a desapropriação de uma parcela da área ocupada, havendo, nesse sentido, o cumprimento de parte da medida compensatória a que o grupo tem direito, tendo sido garantidos apenas 14 hectares até o presente momento. Além disso, há impactos sociais, aqui exemplificados com a construção de benfeitorias, na qual as experiências socioculturais foram invisibilizadas ou menosprezadas.

Constata-se forte articulação política das lideranças Kaingang, que, por, meio da estratégia de alianças, reforçaram a luta por direitos e pela garantia da efetivação de parte das medidas compensatórias e mitigatórias para a coletividade.

Outra relevante percepção evidenciada durante pesquisa de campo na Terra Indígena Jamã Tÿ Tãnh refere-se à apropriação do termo "desenvolvimento" pelos Kaingang. Embora na sociedade não índia, a palavra seja usada em diferentes contextos, pareceu-nos que, para os interlocutores em questão, não é uma palavra comumente usada, tendo em vista que, ao questionarmos a respeito do que eles compreendem por desenvolvimento, houve dúvida, houve necessidade de explicitação do termo, o que reforça a tese de que 


\section{IMPACTOS SOCIOAMBIENTAIS E CONCEPÇÕES DE DESENVOLVIMENTO NO PROCESSO DA DUPLICAÇÃO} DA BR-386 SOBRE A TERRA INDÍGENA JAMÃ TŸ TÃNH, EM ESTRELA, RIO GRANDE DO SUL/BRASIL

"desenvolvimento" é um termo inscrito na cultura do Ocidente. Na lógica indígena, a palavra só tem sentido na relação que se estabelece com a coletividade e na reciprocidade e na sociabilidade interaldeã.

Em relação à lógica indígena de desenvolvimento, evidencia-se que o sentido do termo é pautado pela expansão de suas liberdades substantivas, no sentido de vivenciar práticas culturais e de mobilizar-se pelo espaço sem medo, ter condições de evitar privações como a fome, por exemplo. Também está centrada na garantia de terras para as atuais e futuras gerações, para que possam continuar vivendo de acordo com suas pautas culturais. Por fim, verifica-se que desenvolvimento, para os Kaingang, é uma prática que visa a beneficiar o coletivo, entendida num sentido mais amplo, não no material ou econômico, mas, no sociocultural e socioambiental.

A comunidade indígena Jamã Tÿ Tãnh também centra sua concepção de desenvolvimento na questão da terra, pelo fato de as populações indígenas do sul do Brasil, entre elas os Kaingang, ocuparem, na atualidade, frações dos seus tradicionais territórios, sendo vítimas da espoliação crescente que reduziu o acesso dos povos indígenas à terra, ao longo de sucessivos processos históricos marcados pelo avanço das frentes expansionistas e pioneiras. Assim, desenvolvimento, para os Kaingang da T.I. Jamã Tÿ Tãnh, somente pode ser entendido no sentido plural, no sentido de todos terem acesso à terra, que é muito mais que um elemento constituinte do ambiente, ou seja, é a dimensão holística sobre o ambiente, como espaço de fortalecimento das relações de reciprocidade, de sociabilidade e de sustentabilidade, integrador de sua organização social.

À medida que o desenvolvimento pode ser entendido como uma categoria integradora e global, o etnodesenvolvimento atua como diferenciador da relação indígena com a sociedade não-índia, pautado por uma lógica baseada em princípios de coletividade e de sustentabilidade indígena. Nessa perspectiva, evidencia-se que não há como promover o desenvolvimento indígena, sem considerar a categoria etno no desenvolvimento, considerando o protagonismo indígena em projetos, no caso do presente estudo, vinculado à construção e à gestão da Casa de Artesanato Indígena, que possibilita aos Kaingang renda, interações étnicas, enfim, uma forma de viver na cultura através da produção do artesanato. Tratase de pensar a dimensão social, cultural e ambiental do desenvolvimento, e o etnodesenvolvimento, como instrumento de proteção para um grupo étnico culturalmente diverso.

Para os Kaingang, o território é muito mais cultural do que propriamente um espaço físico e geográfico, que permite tratar de territorialidades resultantes da coexistência de diferentes agentes, com amplas dimensões sóciopolítico-cosmológicas. O território Kaingang comporta vários grupos locais nos quais se distribuem parentes afins. Nesse espaço, grupos familiares e pessoas se movem, formando uma ampla rede de sociabilidade, na qual os sujeitos compartilham experiências e se consideram participantes da mesma cultura.

Compreender a lógica nativa que envolve a concepção de território e de territorialidade é de fundamental importância para entender por que, durante os trâmites da duplicação da BR-386, os Kaingang da Terra Indígena Jamã Tÿ Tãnh decidem incluir as outras áreas situadas em contexto urbano nas cidades de Lajeado, Farroupilha, São Leopoldo e Porto Alegre. Essa decisão passa pela concepção de território como um espaço contínuo, onde os usos e costumes indígenas são colocados explícita e intencionalmente como prática de sua sociabilidade. Ademais, observa-se que a territorialidade dos Kaingang da T. I. Jamã Tÿ Tãnh tem a ver com a apropriação simbólicocultural do espaço e com o fortalecimento de sua identidade cultural. 
IMPACTOS SOCIOAMBIENTAIS E CONCEPÇÕES DE DESENVOLVIMENTO NO PROCESSO DA DUPLICAÇÃO DA BR-386 SOBRE A TERRA INDÍGENA JAMÃ TŸ TÃNH, EM ESTRELA, RIO GRANDE DO SUL/BRASIL

\section{REFERÊNCIAS}

ALMEIDA, L.; FERNANDES, R. C. F. Programa de Apoio às Comunidades Kaingang - Plano Básico Ambiental das obras de duplicação da rodovia BR-386, segmento 350,8 - Km 386,0, com 35,2 km de extensão, jun. 2010.

ANJOS FILHO, R. N. dos. Direito ao desenvolvimento de comunidades indígenas no Brasil. 2009. 761 f. Tese (Doutorado em Direito). Programa de Pós-Graduação da Faculdade de Direito, Universidade de São Paulo (USP), 2009. Disponível em: <http://www.teses.usp.br/teses/disponiveis/2/2 133/tde-05012012-075449/pt-br.php>. Acesso em: 10 set. 2016.

BRASIL. Constituição (1988). Constituição da República Federativa do Brasil. Disponível em: <http://www.planalto.gov.br/ccivil_03/Constituic ao/Constituicao.htm>. Acesso em: 23 jan. 2016.

BRASIL, IBGE - Instituto Brasileiro de Geografia e Estatística. Censo Demográfico 2010: Características gerais dos indígenas. Rio de Janeiro, RJ, 2012. Disponível em: <ftp://ftp.ibge.gov.br/Censos/Censo_Demografic o_2010/Caracteristicas_Gerais_dos_Indigenas/pd f/Publicacao_completa.pdf>. Acesso em: 15 mai 2017.

BUSOLLI, J.. A Terra Indígena Pó Mág, Tabaí/RS no contexto da reterritorialidade Kaingang em áreas da Bacia Hidrográfica Taquari-Antas. 2015. 121 f. Graduação (Monografia). Curso de História, Centro Universitário UNIVATES, Lajeado, 2015.

CABRAL, L. O. Revisitando as noções de espaço, lugar, paisagem e território, sob uma perspectiva geográfica. Revista de Ciências Humanas. Florianópolis, v. 41, n. 1 e 2, p. 141-155, abr./out. 2007.

CASTRO, E. V. de. A natureza em pessoa: sobre outras práticas de conhecimento. In: ENCONTRO "VISÕES DO RIO BABEL". CONVERSAS SOBRE O FUTURO DA BACIA DO RIO NEGRO. Instituto Socioambiental e a Fundação Vitória Amazônica, Manaus. 22 a 25 de maio de 2007. Disponível em: <http://www.socioambiental.org/banco imagens

>. Acesso em: 13 maio 2015.

CERTIDÃO de 17/09/2013 - Inquérito civil no 1.29.014.000070/2009-81. Sobre reunião ocorrida na Aldeia indígena de Estrela. Ministério Público Federal. Lajeado, 17 set. 2013.

DIÁRIO DE CAMPO de 23/05/2016. Pesquisa de Campo na Terra Indígena Jamã Tÿ Tãnh. Projeto de Extensão História e Cultura Kaingang em territórios da Bacia Hidrográfica Taquari-Antas. Lajeado: Univates. 23 maio 2016. 5p.

DNIT. Portal. Duplicação da BR-386 entre Tabaí e Estrela vai beneficiar gaúchos: serviços na "estrada da Produção" já começaram. Brasília, 15 mar. 2011. Disponível em:

<https://www.dnit.gov.br/noticias/duplicacaoda-br-386-entre-tabai-e-estrela-vai-beneficiargauchos>. Acesso em: 10 ago. 2016.

EA e EB - Entrevistado A e Entrevistado B: relato [10 fev. 2016, 9 p.]. Terra Indígena Jamã Tÿ Tãnh, Estrela/RS. Entrevistador: Juciane da Silva. Estrela (RS): s.e., 2016. Gravação em gravador digital. Entrevista concedida ao Projeto de Extensão História e Cultura Kaingang em Territórios da Bacia Hidrográfica Taquari-Antas. Lajeado: Univates.

EF - Entrevistado F: relato [28 jul. 2016, 14 p.]. Terra Indígena Jamã Tÿ Tãnh, Estrela/RS. Entrevistadores: Ernesto Neto, Fabiane da Silva Prestes, Juciane da Silva. Lajeado (RS): s.e., 2016. Gravação em gravador digital. Entrevista concedida ao Projeto de Extensão História e Cultura Kaingang em Territórios da Bacia Hidrográfica Taquari-Antas. Lajeado: Univates.

GALLOIS, D. T.. Sociedades indígenas e desenvolvimento: discursos e práticas, para pensar a tolerância. In: GRUPIONI, Luís Donisete Benzi; VIDAL, Lux; FISCHMANN, Roseli (Org.). Povos Indígenas e Tolerância: construindo práticas de respeito e solidariedade. São Paulo: Editora da Universidade de São Paulo, 2001. p.167-188.

GODOY, A. S. Introdução à pesquisa qualitativa e suas possibilidades. Revista de Administração de empresas. São Paulo, v. 35, n. 2, p. 57-63, 
IMPACTOS SOCIOAMBIENTAIS E CONCEPÇÕES DE DESENVOLVIMENTO NO PROCESSO DA DUPLICAÇÃO DA BR-386 SOBRE A TERRA INDÍGENA JAMÃ TŸ TÃNH, EM ESTRELA, RIO GRANDE DO SUL/BRASIL

Mar/Abri $1995 . \quad$ Disponível em: <http://www.scielo.br/pdf/rae/v35n2/a08v35n2. pdf>. Acesso em: 25 out. 2015.

GONÇALVES, J. R. Relatório Final Antropologia na área de duplicação da BR-386, Triunfo, Tabaí, Taquari, Fazenda Vila Nova, Bom Retiro do Sul e Estrela - RS Aldeia Kaingang TI Estrela. Tubarão: Universidade do Sul de Santa Catarina - UNISUL 2008 (Participação de Alexandre Magno Aquino).

LITTLE, P. E. Territórios sociais e povos tradicionais no Brasil: por uma antropologia territorialidade. Série Antropologia. Brasília, $2002 . \quad$ Disponível em: <http://www.direito.mppr.mp.br/arquivos/File/P aulLittle 1.pdf>. Acesso em: 13 set. 2016.

NOTA TÉCNICA. Programa de Apoio às Comunidades Kaingang. Ministério Público Federal. Brasília, 16 abr. 2012.

OLIVEIRA, J. P. de. Viagens de ida, de volta e outras viagens: os movimentos migratórios e as sociedades indígenas. Travessia: Revista do Migrante. São Paulo. Ano IX, n. 24, p.05-10, jan/abr. 1996.

PARDINI, P. Natureza e cultura na paisagem amazônica: uma experiência fotográfica com ressonância na cosmologia ameríndia e na ecologia histórica. Boletim do Museu Paraense Emílio Goedi. Ciências Humanas. v. 7, n.2, p. 589603, maio-ago. 2012. Disponível em: <http://www.scielo.br/pdf>. Acesso em: 13 maio 2015.

PORTELLI, A. Tentando aprender um pouquinho. Algumas reflexões sobre a ética na História Oral. Projeto História: Ética e História Oral. São Paulo: PPGH- PUC/SP. n.15. Abril de 1997. Disponível em:

<http://revistas.pucsp.br/index.php/revph/article /view/11215>. Acesso em: 23 out. 2015.
ROSA, A. N. da. Relatório de Impacto Ambiental das obras de duplicação da rodovia BR-386/RS, trecho: entr BR-158(A) (DIV SC/RS) - Entr BR116(B)/290 (Porto Alegre), subtrecho: Entr BR453/RS-130 (P/Lajeado) - Entr BR-287(A) (Tabaí), segmento: KM350,8 - KM 386,0, com 35,2 Km de extensão. Brasília, 2009. Disponível em: $<$ http://dnit.gov.br/download/meioambiente/acoes-e-atividades/estudosambientais/br-386-rs.pdf>. Acesso em: 15 jan. 2016.

SEEGER, A.; CASTRO, E. B. V. Terras e Territórios Indígenas no Brasil. In: Encontros com a Civilização Brasileira. Rio de Janeiro, 1979, p.101109.

SEN, Amartya. Desenvolvimento como liberdade. São Paulo: Companhia das Letras, 2000.

SEN, A. Desenvolvimento como liberdade. São Paulo: Companhia das Letras, 2000.

SILVA, J. B. S. da. Territorialidade Kaingang: um estudo histórico da Aldeia Kaingang Linha Glória, Estrela/RS. 2011. 125 f. Graduação (Monografia) Curso de História, Centro Universitário UNIVATES, Lajeado, 2011.

SUSINI, G. M. C. C.; CABRERA, V. C. Algumas considerações sobre desenvolvimento econômico. Âmbito Jurídico, Rio Grande, XIII, n. 78, jul. 2010. Disponível em: <http://www.ambito-

juridico.com.br/site/index.php?artigo id=8106\& n link=revista artigos leitura>. Acesso em: 07 set. 2016.

ZHOURI, A.; OLIVEIRA, R. Quando o lugar resiste ao espaço: colonialidade, modernidade e processo de territorialização. In: ZHOURI, Andréa; LASCHEFSKI, Klemens (org.). Desenvolvimento e Conflitos Ambientais. Belo Horizonte: Editora UFMG, 2010. p. 439-462. 